East African Medical Journal Vol. 83 No. 1 January 2006

PATTERN AND OUTCOME OF ABDOMINAL INJURIES AT KENYATTA NATIONAL HOSPITAL, NAIROBI

P. Musau, MBChB, Department of Surgery, Moi Teaching and Referral Hospital, P.O. Box 4606, Eldoret, Kenya. P.G. Jani, MBChB, MMed, FRCS and F. A. Owillah, MBChB, MMed Cert. (Urology), Department of Surgery, College of Health Sciences, University of Nairobi, P. O. Box 19676, Nairobi, Kenya

Request for reprints to: Dr. P. Musau, Department of Surgery, Moi Teaching and Referral Hospital, P.O. Box 4606, Eldoret, Kenya

\title{
PATTERN AND OUTCOME OF ABDOMINAL INJURIES AT KENYATTA NATIONAL HOSPITAL, NAIROBI
}

\author{
P. MUSAU, P. G. JANI and F. A. OWILLAH
}

\begin{abstract}
Objective: To establish the pattern and results of interventions in patients with abdominal injuries requiring admission.

Design: A descriptive, prospective, hospital-based study involving observation of patients from admission to final outcome of management as either discharged or deceased.

Setting: Kenyatta National Hospital, a tertiary teaching and referral hospital in Nairobi, Kenya, from November 2004 to February 2005 in the adult general surgical wards. Patients: Eighty consecutive admissions of adult patients with either blunt or penetrating abdominal injuries.

Main outcome measures: Type and cause of injury, demographic data, temporal parameters, morbidity and mortality.

Results: The 80 patients had a male to female ratio of 12.3:1, the majority were in the third decade of life with a range 15-56 years and mean of 28.2 years. Penetrating to blunt abdominal injuries had 2:1 ratio with the leading causes of injury being stab wounds, gunshot wounds and road traffic accidents. Blunt abdominal injuries had a higher tendency to extra-abdominal injuries. Duration prior to presentation to hospital and surgery depended on severity of injury. Modes of management varied between attending surgical firms. There was a $20 \%$ change in the mode of management and a $16.1 \%$ rate of negative laparotomy. Penetrating injuries had a better interventional outcome. Penetrating abdominal injuries had higher rates of complications while the blunt injuries had higher rates of mortality. Overall, both the complication and mortality rates were $12.5 \%$. Correlates of mortality included delay before surgery, associated injuries, need for blood transfusion, admission to intensive care unit and duration prior to admission. Abdominal injury patients stayed an average of 6.4 days with the blunt injuries with complications staying close to twice as much as their penetrating counterparts.

Conclusion: Abdominal injuries are a predominantly male disease with the majority in the third decade of life. As opposed to previous studies, gunshot wounds are now a significant cause of abdominal injuries in Kenyatta National Hospital (KNH). The rate-of negative laparotomies has come down by $10 \%$ over the past 15 years. The outcome of management depends on the severity and type of injury sustained.
\end{abstract}

\section{INTRODUCTION}

Trauma continues to occupy a significant position in patient management the world over. With an increasing vehicular traffic, industrialisation, domestic upheavals and general globalisation the developing world is progressively acquiring traits similar to those in the West and gunshot wounds are now more than in the past (1).

Abdominal injuries constitute a significant proportion of patients who present to Kenyatta National Hospital $(\mathrm{KNH})(2)$ yet short of a cursory look, no study has ever been done to establish the pattern and outcome of this problem. Kibosia(3) looked at penetrating abdominal injuries in exclusion of gunshot wounds (GSWs).
Controversies remain on abdominal injuries management with resultant inadequate preparation of surgeons in their management (4). With the introduction of selective management of abdominal injuries in 1960 by Shaftan, the rates of negative laparotomy have progressively decreased (2). This study establishes a $10 \%$ decrease from the $26 \%$ found by Kibosia in 1990. Expectant management of abdominal injuries has also been found to be applicable in gunshot wounds $(5,6)$.

The type of injury determines the likely contents of the abdomen to be hurt $(7,8)$ but this is not a fast and hard rule. Patients with no overt physical findings can have significant intra-abdominal injury while others with penetrating injuries can have negative laparotomy (2). 
While early active intervention is desirable, negative laparotomy has an increase in both morbidity and mortality (9). A delay in appropriate management on the other hand will have similar effects (10).

The management of abdominal injury would need a protocol that takes various parameters into consideration (11). The study suggests adequate resuscitation prior to surgery as well as close observation of the patient with subtle injuries in an effort to reduce negative laparotomies further and prevent avoidable morbidity and mortality in abdominal injuries.

\section{MATERIALS AND METHODS}

Eighty patients with abdominal injuries were recruited into the study. For the purpose of the study, abdominal injury was considered as one that met either or both of the following criteria:

(i) Evident trauma to the abdomen with or without obvious injury to intra-abdominal contents and requiring inpatient care in the general surgical wards.

(ii) Patients involved in multiple injury states such as road traffic accidents or mob attacks but whose main signs and symptoms are ascribable to the abdomen with need for in-patient care as above.

The inclusion criteria were:

(i) Significant abdominal injury requiring admission.

(ii) Patients fit for either conservative or operative modes of management.

(iii) Patients granting informed consent.

Patients who were managed as out-patients, those who were deemed mentally unfit to grant informed consent in the period of the study or any patient who declined to participate in the study, were exempted.
Recruitment into the study by the investigator (P.M.) was at any point from time of admission to the final outcome as long as the patient was in a position to and granted permission to participate.

Data was collected to meet a predesigned questionnaire aimed at establishing the demography, type and cause of injury, duration prior to admission, vital signs at admission, associated injuries, mode of management instituted, duration prior to surgery, complications, admission to ICU, use of blood, duration of stay in hospital and final outcome as to whether discharged or deceased.

Recruited patients were followed up during their stay in hospital for change in mode of management, intra-operative findings and benefit from instituted management.

The duration of stay was taken as the period from admission to when attending surgical firms decided to discharge the patient. Some patients stayed in the wards after this while awaiting clearance of hospital bills but the extra days were not included in the study.

\section{RESULTS}

Out of the 80 patients, 74 were males and six females giving a male: female ratio of 12.3:1. The age ranged from 15 to 56 years, the majority being in the third decade and mean of 28.2 years. The age and sex distribution is as in Table 1.

Fifty three patients had penetrating abdominal injuries while 27 had blunt abdominal injuries giving a ratio close to $2: 1$. The type and causes of abdominal injuries are shown in Table 2. The leading causes of abdominal injuries on the whole, were stab wounds $(42.5 \%)$, gunshot wounds $(21.3 \%)$ and road traffic accidents (RTAs) (15\%).

Table 1

Age and sex distribution of patients with abdominal injuries

\begin{tabular}{lcccc}
\hline Age (years) & Male & Female & Total & $(\%)$ \\
\hline $10-20$ & 12 & 1 & 13 & 16.3 \\
$21-30$ & 41 & 2 & 43 & 53.8 \\
$31-40$ & 15 & 3 & 18 & 22.5 \\
$41-50$ & 3 & 0 & 3 & 3.7 \\
$51-60$ & 3 & 0 & 80 & 3.7 \\
\hline Total & 74 & 6 & 300 \\
\hline
\end{tabular}

Table 2

Causes of abdominal injuries

\begin{tabular}{lcclccc}
\hline & \multicolumn{2}{c}{ Penetrating } & & Blunt \\
\hline Cause of injury & No. & $(\%)$ & Cause of injury & No. & $(\%)$ \\
\hline Stab wound & 34 & 64.2 & & Road Traffic Accidents (RTAs) & 12 & 44.4 \\
Gunshot wound & 17 & 32.1 & Assault & 10 & 37.0 \\
Arrow wound & 2 & 03.7 & & Fall from height & 4 & 14.8 \\
Total & 53 & 100 & & Industrial accident & 1 & 3.8 \\
\hline
\end{tabular}


Fifty two patients had isolated abdominal injuries while the remaining 28 had associated extra-abdominal injuries. Seven patients had more than one extraabdominal injury. The blunt abdominal injuries had higher rates of associated injuries. Associated injuries were to the chest, limbs, head and pelvis.

The duration prior to presentation to hospital depended on the severity of the injury. The severer the injury, the earlier the presentation; ranged from one hour to one week (Table 3).

At the time of presentation, 64 patients $(80 \%)$ had normal vital signs while 16 had deranged vital signs manifest as hypotension, tachycardia, tachypnoea and hypothermia. The relationship between vital signs and outcome of management is given in Table 4.

Patients with abnormal vital signs at admission had $50 \%$ chance of dying. Eighty percent of patients with blunt abdominal injuries with abnormal vital signs died while less than $40 \%(36.4 \%)$ of those with penetrating abdominal injuries with similar findings died, suggesting better interventional outcome in penetrating than blunt abdominal injuries.

Fifty six patients were operated on while 24 were managed conservatively. Six of those operated on were initially managed conservatively, giving a $20 \%$ change in mode of management. Five of the six patients had blunt abdominal injuries and four of them were positive on laparotomy. The one patient with penetrating injury initially managed conservatively was positive on laparotomy. A higher proportion of patients with blunt injuries were subjected to conservative management.

Different surgical firms had different approaches to the management of patients. The operation rates ranged from $56.7 \%$ to $95 \%$ of the patients admitted to the respective surgical firms. One of the firms accounted for $54.2 \%$ of all patients managed conservatively. The admissions, type of injury and mode of management for the respective firms is as shown in Table 5 .

Table 3

Duration from injury to presentation to hospital

\begin{tabular}{lccc}
\hline Duration in hours & Penetrating & Blunt & Total \\
\hline$<6$ & 43 & 17 & 60 \\
$7-12$ & 1 & 1 & 2 \\
$13-18$ & 1 & 0 & 1 \\
$19-24$ & 5 & 5 & 9 \\
$>24$ & 3 & 27 & 80 \\
\hline Total & 53 & & 8 \\
\hline
\end{tabular}

Table 4

Vital signs at admission and outcome of abdominal injuries

\begin{tabular}{lcccc}
\hline & \multicolumn{2}{c}{ Normal Sign } & Abnormal signs \\
\hline Type of injury & Discharged & Died & Discharged & Died \\
\hline Penetrating & 42 & 0 & 7 & 4 \\
Blunt & 20 & 2 & 1 & 4 \\
Grand Total & 62 & 2 & 8 & 8 \\
\hline
\end{tabular}

Table 5

Admission and mode of management according to firms

\begin{tabular}{llcccc}
\hline & & \multicolumn{3}{c}{ Surgical Firms } \\
\hline Type of injury & Mode of Management & I & II & III & Total \\
\hline Penetrating & Operative & 14 & 11 & 15 & 40 \\
& Non-operative & 6 & 6 & 1 & 13 \\
\multirow{3}{*}{ Blunt } & Sub-total & 20 & 17 & 16 & 53 \\
& Operative & 6 & 6 & 4 & 16 \\
& Non-operative & 4 & 13 & 4 & 27 \\
\hline \multirow{2}{*}{ Total } & Sub total & 10 & 30 & 20 & 80 \\
\hline
\end{tabular}


The overall rate of operation was $70 \%$. Of the operated patients, nine had no surgical pathology, giving a negative laparotomy rate of $16.1 \%$. Seven out of the nine patients with negative laparotomies had normal vital signs. The two with deranged vital signs had associated extra-abdominal injuries. A third of the patients had omental extrusion. On the whole, negative laparotomy patients had an average delay of 14.3 hours prior to surgery, almost double the average 7.5 hours for those with positive laparotomies. The features, therefore, likely to suggest possibility of negative laparotomies were omental extrusion, stable patients who remain so to allow delayed surgery and hypotension that may be accounted for by extraabdominal injuries.

The duration prior to surgery varied according to severity of condition and whether or not it was primary decision to operate. Patients that were initially managed conservatively took longer to be taken for operation (Table 6).

Penetrating abdominal injuries had a greater variety of possible intra-operative findings. While penetrating injuries had affected the gastrointestinal tract (GIT) and related structures most, the sum total of injuries to solid viscera (liver, spleen and kidneys) and urinary bladder was more than injuries to the intestines in blunt abdominal injuries.

Ten patients developed complications, giving $12.5 \%$ complication rate. The complications included rebleed, sepsis, gangrene of anterior abdominal wall and enterocutaneous fistulas.

Ninety percent of the complications arose in patients with penetrating injuries. A similar percentage of complications arose in those who had suffered single or multiple injuries to the gut.

The complications were high in the first half of the first day of injury, declined in the second half and then started rising in the second day.

Eight patients (10\%) were admitted to ICU, five of whom died, giving a $62.5 \%$ mortality rate for this group of patients.

Twenty three patients $(28.8 \%)$ - fifteen with penetrating and eight with blunt injuries had blood transfusion. Twenty one of these were operated on while two were managed conservatively; there were 19 positive and two negative laparotomies. The multiplicity of injured organs in patients with penetrating injuries, which stood higher chance of surgery than blunt injuries, could account for use of blood in these patients.

Ten patients (six with blunt and four with penetrating injuries) succumbed to their injuries: five road traffic accident (RTA) victims, three GSWs and one each stab wound and fall from height. Eighty percent of the deaths occurred in patients with associated extra-abdominal injuries. The other correlates with mortality were duration prior to surgery, duration prior to admission, admission to ICU and use of blood in the management (Table 7).

Table 6

Duration of stay prior to surgery

\begin{tabular}{|c|c|c|c|c|c|c|}
\hline \multicolumn{4}{|c|}{ (a) Primary surgery } & \multicolumn{3}{|c|}{ (b) Surgery after initial conservative management } \\
\hline \multirow{2}{*}{$\begin{array}{l}\text { Duration prior } \\
\text { to surgery in } \\
\text { hours }\end{array}$} & \multicolumn{3}{|c|}{$\begin{array}{l}\text { Number of patients per } \\
\text { injury }\end{array}$} & & \multicolumn{2}{|c|}{ Type of injury } \\
\hline & Penetrating & Blunt & Total & & Penetrating & Blunt \\
\hline$\leq 6$ & 18 & 5 & 23 & Duration in hours & 24 & $\begin{array}{l}14,20,48, \\
120,120\end{array}$ \\
\hline $7-12$ & 11 & 4 & 15 & $\begin{array}{l}\text { Average duration } \\
\text { in hours }\end{array}$ & 24 & 64.4 \\
\hline $13-18$ & 8 & 1 & 9 & & & \\
\hline $19-24$ & 2 & 1 & 3 & & & \\
\hline$>24$ & 0 & 0 & 0 & & & \\
\hline Total & 39 & 11 & 50 & & & \\
\hline
\end{tabular}

Table 7

Indicators of mortality in abdominal injuries

\begin{tabular}{|c|c|c|c|c|c|c|}
\hline \multirow[b]{2}{*}{ Duration in hours } & \multicolumn{3}{|c|}{$\begin{array}{l}\text { Deaths with relation to duration } \\
\text { prior to admission }\end{array}$} & \multicolumn{3}{|c|}{$\begin{array}{l}\text { Deaths with relation to duration } \\
\text { prior to surgery }\end{array}$} \\
\hline & Total & $\begin{array}{l}\text { No. admitted } \\
\text { to ICU }\end{array}$ & $\begin{array}{l}\text { No. } \\
\text { Transfused }\end{array}$ & Total & $\begin{array}{l}\text { No. admitted } \\
\text { to ICU }\end{array}$ & $\begin{array}{l}\text { No. } \\
\text { Transfused }\end{array}$ \\
\hline$\leq 6$ & 8 & 5 & 7 & 4 & 2 & 4 \\
\hline $7-12$ & 1 & 0 & I & 2 & 2 & 2 \\
\hline $13-18$ & 0 & 0 & 0 & 0 & 0 & 0 \\
\hline $19-24$ & 0 & 0 & 0 & 0 & 0 & 0 \\
\hline$>24$ & 1 & 0 & 0 & 1 & 1 & 1 \\
\hline
\end{tabular}


Eighty percent of the dead presented within the first six hours of injury. Deaths occurred in the extremes of time: too early or too late, leaving a deathfree second half of the first day of injury. Of those who died after surgery, $57.1 \%$ had been operated on within six hours of admission. This can be accounted for by the state of patient and inadequate time for resuscitation prior to surgery.

Eighty percent of those who died required blood transfusion. All those who died after surgery had blood transfusion, $71.4 \%$ of whom had ICU admission.

The foregoing suggests that severely injured patients presented early, were subjected to surgery early, required blood transfusion and ICU admission as part of the management and succumbed to the injuries, making these factors strong indicators of mortality in abdominal injuries.

Majority of patients stayed up to five days; $88.6 \%$ were discharged within 10 days (Table 8).

Table 8

Type of injury and the duration of in-patient stay

\begin{tabular}{lccc}
\hline Days & Penetrating & Blunt & Total \\
\hline$\leq 5$ & 20 & 12 & 32 \\
$6-10$ & 24 & 6 & 30 \\
$11-15$ & 3 & 2 & 5 \\
$16-20$ & 1 & 1 & 2 \\
$>20$ & 1 & 0 & 1 \\
\hline Total & 49 & 21 & 70 \\
\hline
\end{tabular}

The duration of stay was predicated on whether or not there were associated injuries or resultant complications. There was no significant difference between the type of injury and duration of stay for the uncomplicated, isolated injuries. For the abdominal injuries with complications, the duration of stay in patients with blunt trauma was longer than in those with penetrating injuries. On the whole, the average duration of stay for all the abdominal injuries was 6.4 days.

\section{DISCUSSION}

Abdominal injuries have remained a challenge to surgeons with an ever-present desire to improve on the outcome of the management.

Eighty patients were recruited and as in other studies elsewhere, the male predominance was striking. The male to female ratio was 12.3:1 and this compared well with other studies. Edino in Kano, Nigeria (12), in his study on pattern of abdominal injuries had a sample of 67 males with no females. McFarlane in Kingston, Jamaica, found a ratio of 10:1 male to female (13). Closer home, two previous studies conducted in Kenyatta National Hospital $(2,3)$ had male to female ratio of 11.5:1 and 12.7:1 respectively. While the actual ratios may vary from study to study, male dominance stands out and studies conducted in similar environmental setting and closer in time have ratios that are the same as evidenced by Githaiga's (2) 12.7:1 and this study's 12.3:1 in the same setting and a difference of nine years.

Fifty three patients had penetrating abdominal injuries, making penetrating to blunt abdominal injuries almost 2:1. Most of the studies reviewed have been done on specific types of abdominal injuries (either blunt or penetrating separately). Edino (12) in his study on pattern of abdominal injuries found penetrating to be more than blunt. His $53.7 \%$ for penetrating injuries compares well with our $66.3 \%$. Exadaktylos et al (14) in South Africa found the two injuries to be $80 \%$ penetrating and $20 \%$ blunt.

The causes of abdominal injuries vary from place to place and have also been noted to change with time. Within a decade, gunshot wounds increased by $800 \%$ while admissions remained unchanged in a study done in South Africa (7). Adesanya et al., in a study on civilian gunshot -wounds in Lagos noted a ten-fold increase in a decade (1). In Kenya, Kibosia (3) in 1990 undertook a study on stab wounds only and so had no mention of gunshot wounds to the abdomen. Fourteen years later, this study had gunshot wounds (GSWs), accounting for $21.3 \%$ of the abdominal injuries. This is in keeping with societal advancement that has yielded violent crimes and social conflicts (12). Sixteen of these GSWs were crime-related and the remaining one was an attempt at suicide. Stab, gunshot and arrow wounds were the causes of penetrating abdominal injuries while road traffic accidents (RTAs), assault and fall from height were responsible for blunt injuries. On the whole, the leading causes of abdominal injuries in this study are stab, GSWs and RTAs. It would be interesting to see how these causes change in the future.

Thirty five percent of the abdominal injuries had associated extra-abdominal injuries as well. They were found to be more in blunt than penetrating abdominal injuries. This can be accounted for by the causes of injury; RTAs and assault as the leading causes of blunt injuries have a higher likelihood of there being other injuries elsewhere than stab and GSWs to the abdomen.

Presentation to hospital after injury depended on the severity. The shortest was one hour and the longest one week. There was no difference between the type of injury and the time taken prior to presentation, emphasising the fact that degree of injury was more important than the type. Seventy five percent of the patients presented within six hours of the injury. Kibosia had the same findings $(75 \%)$ over ten years ago (3). This may be a testimony to the dramatic events surrounding abdominal injuries and the need to seek medical attention in most cases. From the medical perspective this tells us that there is ample time for effective management of patients who present early. 
Twenty percent of the patients had abnormal vital signs, principally manifested as hypotension at admission. A striking finding is the $80 \%$ mortality in patients with blunt abdominal injury and attendant derangement of vital signs. Patients with penetrating abdominal injuries with deranged vital signs fared better than similar ones with blunt injuries. The morbidity and mortality exhibited in patients taken for surgery after early presentation may be explained by the severity of condition and risk of surgery in patients who are yet to be adequately resuscitated. This study brings to the fore the risk of rushed surgical intervention in a patient not fully stabilised after trauma.

There is no room for dogma in the management of abdominal injuries. Findings that were scientifically sound in a given study have been found unacceptable in others. While McFarlane in his paper on management of penetrating abdominal injuries espoused a policy of mandatory explorative laparotomy in GSWs (13), three other studies in review concluded that it is possible to manage GSWs to abdomen conservatively $(5,15,16)$. This was found to be true in our study where two GSWs were managed conservatively and one was subjected to a negative laparotomy. Negative laparotomies in GSWs had-also been noted by Adesanya in Lagos (1) six years ago. Ivatury and colleagues (16), in a study on missile wounds of the abdomen successfully managed $60 \%$ of them conservatively.

Kibosia (3) had included positive paracentesis and omental evisceration as indicators for laparotomy. While Nagy et al.,(17) found up to $75 \%$ of patients with evisceration, regardless of what eviscerated, required laparotomy, a third of the patients in our study with negative laparotomy had omental extrusion. Nagy et al (18)., in another study, found that aspiration of blood in abdominal injury need not necessarily lead to laparotomy. This we found true in our study since the two patients with positive paracentesis for blood but stable were successfully managed conservatively.

From the foregoing, it becomes evident that management of abdominal injuries requires a protocol that pays great attention to the condition of the patient (11). To aid in decision making, laparascopy and diagnostic peritoneal lavage (DPL) have been put into use. Ultrasound, plain abdominal X-rays, CT scan and contrast studies have also been employed to aid in diagnosis. DPL has been found to be superior to radiology $(10,18)$ but like laparascopy, requires stable patients and so has limited application. CT scan in stable patients is increasingly gaining currency in decision making especially where previous abdominal surgery excludes use of DPL in patient assessment $(2,18)$.

Githaiga and Adwok (2) found DPL to be easy to perform, cheap and highly effective in diagnosing the injured abdomen in need of laparotomy. The standard indications for laparotomy from previous studies remain haemodynamic instability, peritonitis, free air under the diaphragm or fresh blood on rectal exam or in nasogastric tube $(3,4,6)$. Our study identified the following as possible indicators of a likely negative laparotomy: isolated omental extrusion, a stable patient who remains so up to and including the time of a relatively delayed laparotomy and hypotension that can be explained on the loss from extra-abdominal injuries.

The overall operative rate was $70 \%$. Eighty percent of those started on conservative management benefited. The mode of management varied from surgical firm to other, signalling the varied approaches to abdominal injuries. One of the firms had a $95 \%$ rate of operation while another accounted for $54.2 \%$ of all patients managed conservatively. This is a pointer to the daunting task of effectively managing abdominal injuries.

A rate of $16.1 \%$ for negative laparotomies is impressive not only because of the varied approaches to management in the admitting surgical firms but also because of its being an indication of progress in better management compared to previous studies in $\mathrm{KNH}$. Kibosia had noted a $50.8 \%$ rate of negative laparotomies before his finding of $26.1 \%$. This has come down by $10 \%$ in a period of 14 years. In a study to assess how effective DPL is in the management of abdominal injuries, Githaiga and Adwok (2) realised a 6.9\% rate of negative laparotomies. This means there is more room for improvement on patient selection and when to operate on patients with abdominal injuries. Elsewhere, thee rates vary from $7 \%$ to $40 \%(8,9,13,19)$.

There was greater variety of intra-operative findings in penetrating injuries. This is on account of depth of penetration and injured structures in the trajectory path, particularly in cases where GSWs was the cause of injury. The findings in this study are in keeping with previous studies elsewhere that confirmed that the gastrointestinal track is injured most in penetrating than blunt injuries $(6,10,12)$. Injury to the gut in blunt abdominal injury is uncommon (8) but not a rarity. In this study, six out of seventeen intra-abdominal findings were injury to the small intestines. When seen in the light of injuries to solid organs and urinary bladder, gut injury after blunt trauma to abdomen remains of a smaller proportion as previously found in other studies conducted elsewhere $(8,10,12)$.

There was a complication rate of $12.5 \%$, comparing well with other studies. Stewart et al.,(10) had a complication rate of $16 \%$. The reviewed studies show that complications depend on type of injury, organinjured and duration prior to surgery. In this study, $90 \%$ of the complications arose in penetrating abdominal injuries, 90\% arose after laparotomy and 90\% had single or multiple intestinal injury. The complications were noted to be more in those who had operations either early or late, showing the degree of trauma and effect of delayed surgery in complications after abdominal trauma. The more severely injured patients 
stood a higher chance of early surgical intervention, hence this peak. The other peak could be accounted for in terms of effects of delay after intra-abdominal injuries to the gut and viscera with ensuing peritonitis and wound contamination during laparotomy. Frequent observations and examination in those with subtle abdominal injuries would identify the patient unlikely to benefit from conservative management. This would ensure surgery in good time where indicated and thus reduce morbidity and mortality arising from delays in intervention.

Mortality in this study was $12.5 \%$. Sixty percent of this was accounted for by blunt abdominal injury. Mortality was found to relate to type of injury (blunt>penetrating), admission to ICU, blood transfusion, delays in appropriate intervention, time taken from injury to admission, and from admission to surgery and the causative agent. Patients who were severely injured presented early, were subjected to surgery early, needed blood transfusion and ICU admission and tended to succumb to their injuries, particularly if presenting in shock. Delayed presentation to hospital and delayed surgery in excess of 24 hours was also noted to contribute to mortality. While other studies have mentioned the contribution of time prior to admission and surgery to mortality, this study draws attention to the deleterious effect of rushed surgery in trauma patients. Attempts should be made to correct the physiological changes before or during surgery to optimise the outcome.

The overall duration of stay in this study was 6.4 days. There was no difference in this duration for simple, uncomplicated injuries to abdomen whether penetrating or blunt. For the complicated ones, patients with blunt injuries stayed almost twice the duration taken by those with penetrating injuries. This study compares, favourably with that done by Githaiga and Adwok (2) which showed an average of 6.5 days' hospital stay prior to discharge. This would suggest a uniform policy on indications for discharge across the three surgical units.

\section{ACKNOWLEDGEMENT}

To the University of Nairobi for allowing us to publish this paper that was initially in the form of MMed dissertation.

\section{REFERENCES}

1. Adesanya, A.A., Afolabi, I. R. and da Rocha-Afodu, J. T. Civilian abdominal gunshot wounds in Lagos. J. Roy. Coll. Surg. Edin. 1998; 43: 230.
2. Githaiga, J. W. and Adwok J. A. Diagnostic peritoneal lavage in the evaluation of abdominal trauma using the dipstick. East. Afr. Med. J. 2002; 79: 457-460.

3. Kibosia, J. C. A study of some aspects of management of penetrating stab wounds (PASW) at KNH. MMed. dissertation, University of Nairobi, 1990.

4. Brooks, A., Butcher, W., Walsh, M., et al. The experience and training of British general surgeons in trauma surgery for the abdomen, thorax and major vessels. Ann. Roy. Coll. Surg. 2002, 84: 409-413.

5. Chmielenski, G. W., Nicholas, J. M., Duchavsky, S. A., et al. Non-operative management of gunshot wounds of the abdomen. Amer. Surg. 1995, 61: 665-668.

6. Smith, R. C. and Oleeary, J. P. To cut or not to cut: the evalution of exploratory laparatomy for abdominal gunshot wounds. Amer. Surg. 1999; 65: 388-389.

7. Muckart, D. J., Meumann, C. and Botha, J. B. The changing pattern of penetrating torso trauma in Kwazulu/Natal: a clinical and pathological review. South. Afr. Med. J. 1995; 85: 1172-1174.

8. Jani, P. G., Abdel-Aziz, I. S. and Yajnik, K. N. Duodenal perforation following blunt abdominal trauma: case report. East Afr. Med. J. 1998; 75: 669-670.

9. Leppaniemi, A., Salo, J. and Haapianen, R. Complications of negative laparotomy for truncal stab wounds. J. traumainjury, Inf. Crit. C. 1995; 38: 54-58

10. Stewart, B. T., Lee, V. and Danne, P. D. Laparotomy for trauma in a regional centre: the effect of delay on outcome. Aust. N. Z. J. Surg. 1994; 64: 484-487.

11. Rosemurgy, A. S., Albrink, M. H., Olson, S.M., et al. Abdominal stab wound porotocol: prospective study documents applicability for widespread use. Amer. Surg. 1995; 61: 112-116.

12. Edino, S. T. Pattern of abdominal injuries in Amimu Kano Teaching Hospital, Kano. N. Postgrad. Med. J. 2003;10: 56-59

13. McFarlane, M. Management of penetrating abdominal injuries. W. Indian Med. J. 1995; 44: 140-142.

14. Exadaktylos, A., Stettbacher, A., Edul, S., et al. Successful management of abdominal stab wounds with clinical evaluation: experiences of a South-African trauma unit with 496 consecutive patients. Unafall Chirurg. 2003; 106: $215-219$.

15. Sosa, J. C., Arrigalla, A., Puente, I., et al. Laparascopy in 121 consecutive patients with abdominal gunshot wounds. J. Trauma-Injury Inf. Crit. C. 1995; 39: 501-504.

16. Ivatury, R. R., Simon, R. J. and Stahl, W. M. Selective celiotomy for missile wounds of the abdomen based on laparascopy. Surg. Endosc. 1994; 8: 366-369

17. Nagy, K., Roberts, R., Joseph, K., et al. Evisceration after abdominal stab wounds: is laparatomy required? J. Trauma 1999; 47: 622-624.

18. Nagy, K. K., Fildes, J. J., Sloan, E. P., et al. Aspiration of free blood from peritoneal cavity does not mandate immediate laparatomy. Amer. Surg. 1995; 61: 790-795.

19. Subramaniam, P., Parker, S., Lim, et al. Review of liver trauma management in Tasmania: Analysis of risk factors for mortality and morbidity. Aust. N. J. Surg. 1995; 65: $861-864$ 